\title{
Hydrogeology of arid and semiarid environments
}

\author{
Randolf Rausch $^{1}$ - Christoph Schüth ${ }^{1}$ Heidi Megerle ${ }^{2}$
}

Received: 30 May 2017 / Published online: 18 December 2017

(c) Springer-Verlag GmbH Deutschland, ein Teil von Springer Nature 2017

Many of our society's future challenges will be linked to geosciences. In particular, the limited availability of georesources, like water, soils, fossil and renewable energies are of great concern. This has been emphasized by the "geocommission" of the German Research Foundation in their recently published strategic paper on the future challenges of geosciences.

Water is an essential resource. It is widely predicted that global water consumption will double, from the consumption levels of the 1960's to that predicted in 2025. Already in many arid and semiarid environments water resources are dramatically overexploited, and it has to be admitted that a sustainable use of these resources is difficult or even unrealistic.

Smart and efficient concepts are needed to manage water resources with the greatest possible benefit for our society. This requires a fundamental understanding of local and regional hydrogeology, hydrochemistry and hydrody- namic processes, as well as a precise quantification of water resources. Good management can be achieved only on a robust data basis rather than based on pure estimates.

For scientists-especially hydrogeologists - this represents a great challenge and responsibility, and at the same times an excellent opportunity. The objective of our research is to better understand the dynamics of groundwater resources under changing climate and hydrological conditions and to address the challenges of managing groundwater resources in arid and semi-arid environments.

This special issue Grundwasser focuses therefore on all aspects of the management of (ground)water resources in arid environments, from the assessment of the water cycle and the quantification of groundwater resources, to engineering approaches and aspects of economy.

It is our hope that the publications in this issue of Grundwasser will improve our understanding of the hydrogeology of arid and semiarid environments and help us to solve the crucial water problems in these regions.

Randolf Rausch

randolf_rausch@yahoo.de

Christoph Schüth

schueth@geo.tu-darmstadt.de

Heidi Megerle

megerle@hs-rottenburg.de

1 Institut für Angewandte Geowissenschaften, Technische

Universität Darmstadt, Schnittspahnstr. 9, 64287 Darmstadt, Germany

2 Ressourcenmanagement Wasser, Hochschule für Forstwirtschaft Rottenburg,

Schadenweilerhof, 72108 Rottenburg a. N.,

Germany 